\title{
FACIAL CAPTURE AS A MEASURE TO SOLVING CBT EXAMINATION MALPRACTICES
}

Adesina, Ademola Olusola and Oyenuga, Ayodeji

Department of Mathematical Sciences, OlabisiOnabanjo University, Ago-Iwoye, Nigeria.

Corresponding author: ademola.adesina@oouagoiwoye.edu.ng

\section{ABSTRACT} The adoption of Computer Based Testing (CBT) by Nigerian Tertiary Education Institutions has processing. The most prominent of these challenges is the impersonation and to tackle these eventualities, multi-layered security architecture is implemented to ensure the authenticity of the student participating in the CBT. The architecture will assist Nigerian University administrators to effectively plan the conduct of CBT and develop in-house solution that will engender the reduction in the examination malpractices in CBT. The introduction of the facial capture reduced the intents of the students in engaging in the act of impersonation. The first security layer is the profiling of the registered students that are eligible to partake in the test, the second layer is the biometric capture to identify and authenticate that the student is the original person to partake in the test. The third layer is the facial capture on the system before the com aned and implemented using algorithmic approach and a web-based application which will be deployed on the LAN of the institution. Therefore, this research presents the implementation of the multi-tiered layered security in mitigating the incidences of impersonation during CBT.

Keywords: Computer Based Test, Exam Malpractices, Facial Capture

Accepted Date: 30 May 2018

\section{INTRODUCTION}

Measuring the capability of students in teaching and learning through continuous assessment $(\mathrm{CA})$ has been rated high in various levels of educationa system. CA is seen as a classroom strategy implemented by teachers to ascertain the knowledge, understanding, and skills attained by pupils. Teachers administer assessments in a variety of ways over time to allow them to observe multiple tasks and to collect information about what pupils know, understand, and can do (Onuka \& Durowoju, 2011). For lecturers, when students' performances are high, it is obvious that they have transferred knowledge appropiately to the students. On the other side, i.e. for the learners/students, high (CA) performance mean good grades, and this implies better opportunitie to further/continue education and good chance for job placement. Assessment systems provide the ways to measure individual and institutional success, and so can have a profound driving influence on systems they were designed to serve
(Resnick \& Resnick, 1992). As part of the assessment, it is a normal process in educational system to conduct series of examinations before a session can be completed. The common or predominant form of conducting examinations in Nigeria is the traditional method. In this method, students are assessed by pen and paper method on cognitive abilities. The pen and paper method is characterized by various setbacks and threats like high cost of paper malpractices, questions leake, missing scripts, delayed in release of results, inpersonations, extortion of money by lecturer or head of class, sexual harassment from the opposite sex with the gain of earning marks, bringing of written materials or phones into the exam halls and many more.

Examination malpractice is any illegal act committed by a student single handedly or in collaboration with others like fellow students, parents, teachers, supervisors, invigilators, printers and anvody or group of people before, during or and anbody or group of people befe, duning or marks or grades (Olatoye, 2013). The use of 
computers in form of Computer Based Testing CBT) for assessment can provide several benefits for educators and test-takers. which spurs development in education as well as other sectors of the economy (Festus Oladimeji, 2017; Ogunlade (2014). CBT usully 2017; Ogunlade 作 (4) efficiently cross-checked. It is also an efficient way for test sponsors to provide a secure, consistent environment for certification and licensure as it also enhances students' experience (Abubakar \& Adebayo, 2014; Mardapi \& Rahmi, 2015). The successes of transition from one test method depends on the extent and ability of testing professionals to communicate the benefits and imitations of t (Jitations of that test me (Jones, 2000; Leeson, 2006)

Computer Based Testing is the use of computer in assessing a student (Peat \& Franklin, 2002). The advantages of CBT are enormous over pen and paper testing, for instance, the problems faced (like space, missing script etc.) when general or compulsory courses that are taken by large classes have been solved. Problems encountered by students during and after tests and examinations are curbed with the new technological method. The ecturers are also relieved from the burden of marking large answer scripts and probably scripts lost in the process of moving the script from one place to another. The cost of production of printing papers is brought to minimum level; this is indirectly an economic gain to the institution as it reduces the administration costs. Examination leakages are eliminated and there is an end-to-end electronic audit trail to know who assessed what and when. There is availability of randomness in he loading of questions for each student, and this emoves the probability of helping one another in the course of doing the examination within the examination hall (Funke, 1998; Kleinmann \& Strauß, 1998; Tella \& Bashorun, 2012).

However, there is no system that does not have its peculiar challenges. CBT has proved to be a solution to the students' authenticity and eligibility for test/examination. Students' details like Surname, Student Number/Matric. No. can be used to gain access to examination. With these details the case of impersonation is made possible. Hence crise friends/colleagues can sit for others conveniently to conduct examination for others. This is the exact
impersonation problem that existed and being

faced in the conduct of examination through the pen and paper approach. Having this experience, is therefore important to build another layer of security in order to combat the impersonation cases which arise as a result of the use of the and the mich as as a result of the use of the for this research is to add another security layer to the CB application system. The layer is expected to activate the candidate facial images that have bee captured before and during the test assessments. The scope of this study is focused on the students that participated in the General courses of Tai Solarin University of Education (TASUED), via the use of the CBT application. TASUED is a university of education in Nigeria. It was unisty of 2005 and located in Ijagun, Ijebuestablished in 2005 and located in ljagun, ljebuOde, Ogu State. The university was named after the Nigerian educational administrator and huma rights activist Tai Solarin.

\section{SYSTEM DESIGN AND RESEARCH} METHODOLOGY

This section describes the system design for the project and research methodology

\section{SYSTEM DESIGN}

The facial capture module is introduced to enhance the security of the CBT system. It was made optional in a situation where the CBT application system does not have a web camera attached to it by either activating or deactivating the module from the Admin end. Once activated, the CBT application system will not proceed to the test page for the student until an image is captured via the posing the application syste (n) in-built camera or detachable camera, the Administrator can decide to de-activat the image capture module. It was designed as a module and integrated using an Application Programming Interface (API). The CBT architecture is designed to be of 3-tier architecture which is presentation tier, logic tier and database tier. The presentation tier serves as an interface to the users, the logic tier serves as the middleware requests and the database tie serves as the repository of all the data requied to the take the assessments. The initial architecture supports the username and password login module, and takes you to the test page where every student's

passports are displayed. Fig. 1 shows the University assessment page

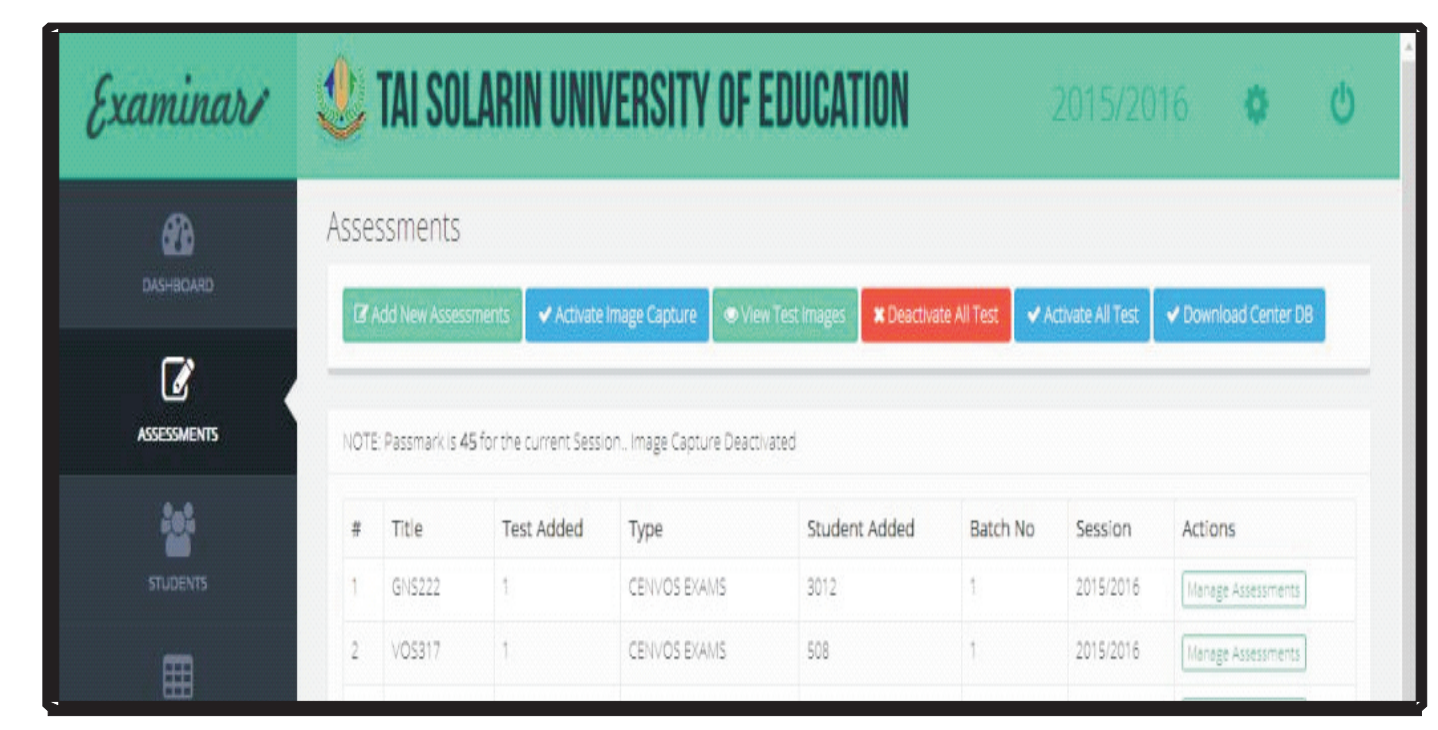

Fig. 1: University Assessment page

\section{RESEARCH METHODOLOGY}

The process flow is such that the student will $\log$ in with the usual login details which is Matriculation Number as the User name and Surname as the Password. There is a user table that contains all students that have paid for the session. The login authentication eligibility and if the name is not found there, the system displays "incorrect username and password" message. If found, it goes on to generate questions and randomize it to remove the chances of the students teaching themselves during the assessment. No two students can have same questions occurring in the same sequence. Once the student answers all the questions, the student ends exams or when the time elapsed, the system automatically logs you out and end exams. Fig. 2 hows flowchart ligitity and auth randomized questions can be presented. The examination period for the particular course (GNS 111 ) is 10 minutes for a maximum of 30 questions. GNS 111 is a compulsory course for all fresh students in the College of Science and Info Technology. This \& opportunity for testing the proposed biometric system. Like any other higher institution, registration of the fresh students is done per session in TASUED. Student personal bio-data like names, Matric. Number, age, gender, home address, parent-address, educationa background are captured. The webcam is used to take the picture of the student and it is converted into .jpg format. The picture is then placed in the $25 \mathrm{~mm}$ by $25 \mathrm{~mm}$ photo-box created in the CBT application system. The picture that was taken is registration number. 


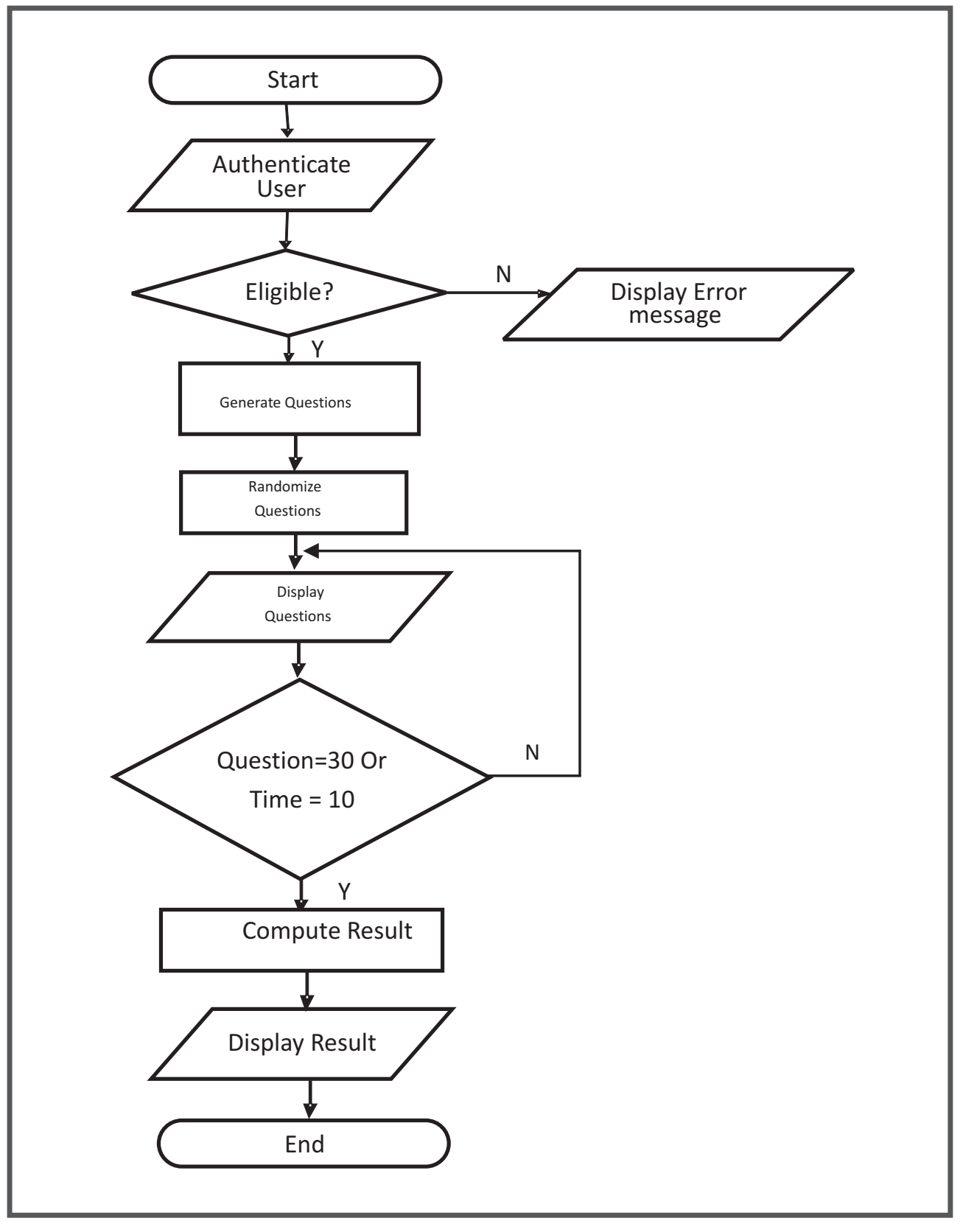

Fig. 2: CBT system flowchart

Within the time frame allocated for the GNS 111 examination; 3 snapshots of candidates are taken at random with different orientation. This set of images is taken in different angles as part of the presentation layer. The image is then compared with the pictures that had been saved in the folder with the pictures that had been saved in the folder
(database layer). Any dissimilarity in the pictures will give room for suspicion (See Fig. 3). When the pictures are similar the candidate will be able to continue with the examination.There is a possibility that the student may attempt to cover the face of the web camera to take a black picture, the admin side is equipped with a page called Image capture that displays all the pictures taken in real time and once any of such is discovered, the admin logs the person out by clicking the reset button. The user immediately receives a message on the screen that "you have been logged out from the system because the passport taken is bad" The New Architecture of the proposed CBT system with facial capture module is displayed in Fig. 3

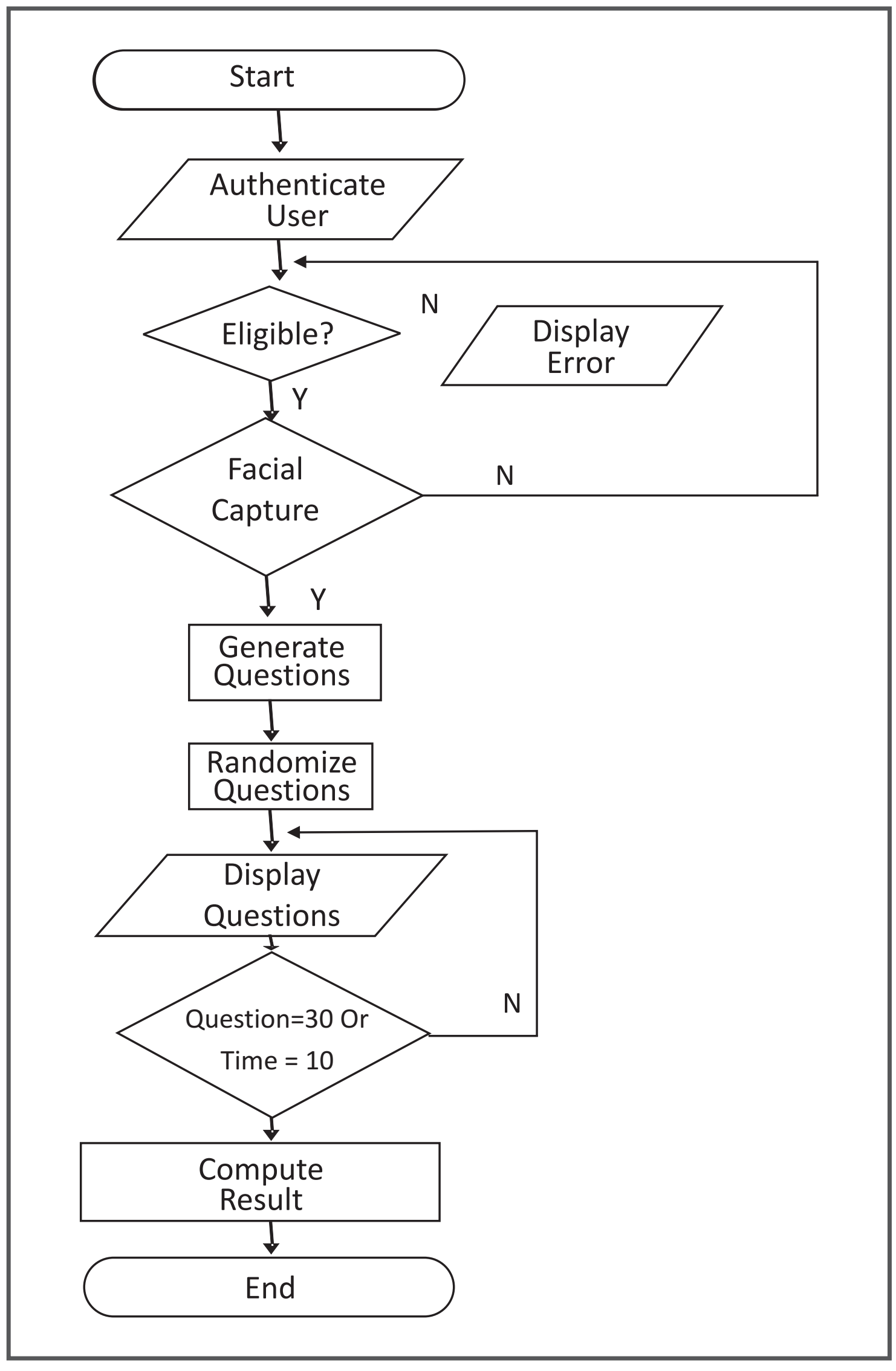

Fig. 3: Data validation for the facial images captured 
In the new CBT Architecture with facial capture integration as a security layer, at the point of generating questions, it prompts for a picture to be aken before generation of questions. Once the picture is taken, it is displayed alongside with the picture is take, it is displayed al passo the in plisper disparity between the picture taken and the passport in the database.

\section{RESULTS}

Before the introduction of the new CBT system with facial capture integration, the students engage in impersonation to either assist a student who is not

\section{Table 1: Results of performance for the proposed method}

\begin{tabular}{|c|c|c|}
\hline Session & $\begin{array}{l}\text { Number of candidate for } \\
\text { GNS } 111 \text { examination }\end{array}$ & $\begin{array}{l}\text { Number of } \\
\text { Impersonator }\end{array}$ \\
\hline $2013 / 2014$ & 2560 & $\begin{array}{c}135 \\
\text { (Paper and pen exam) }\end{array}$ \\
\hline $2014 / 2015$ & 2520 & $\begin{array}{c}111 \\
\text { (First use ofCBT) }\end{array}$ \\
\hline $2015 / 2016$ & 2000 & $\begin{array}{c}90 \\
\text { (Second use of CBT } \\
\text { with CCTV) }\end{array}$ \\
\hline $2016 / 2017$ & 2525 & $\begin{array}{c}2 \\
\text { (Facial capture } \\
\text { integration) }\end{array}$ \\
\hline
\end{tabular}

The awareness and implications of impersonation is getting high within the University system. Any student caught in the act is rusticated from the University. It is obvious that since the students know the possibility of been caught is high, they abstained totally from the act of impersonation.

\section{CONCLUSION}

When fully implemented it is expected that the design and architecture will assist not only TASUED but also any other higher institution to cope with the menace of examination malpractices hrough impersonations. Another area that can strengthen the purpose of achieving impersonation-free University examination is for the school authority to work the students' attitude so that they are aware of the consequence of their around to partake in the test or to help a weak student in conducting the tests. The login credentia is just the matriculation number and the passwords, a student can log in on behalf of the oter person. Below is a table showing the result acheved the integration of the facial capture. This Bex interis ar the facial capture. This per conducted over a series of four (2013/2014, 2014/2015, $2015 / 2016$ and 2016/2017). There has been a remarkable achievement from the use of Paper and in the corresponding manners of $5.27 \%, 4.41 \%, 4.5 \%$ and $0.08 \%$ integration)

actions. Proper implementation of the biometric technology will also assist the school administrators to effectively plan the $\mathrm{CB}$ examination for all other courses as well as result processing.

\section{REFERENCES}

Abubakar, A. S., \& Adebayo, F. O. (2014). Using computer based test method for the conduct of examination in Nigeria: Prospects, challenges and strategies. Mediterranean Journal of Social Sciences, 5(2):47.

Festus Oladimeji, O. (2017). Students' Perception of Computer-Based Test in Nigerian Universities. Nigerian Journal of
Educational Technology, 1(2):117-129.

Funke, J. (1998). Computer-based Testing an Training with Scenarios from Complex Problem-solving Research: Advantages and Disadvantages. International Journal of Selection and Assessment, 6(2):90-96.

Jones, J. P. (2000). Promoting stakeholder acceptance of CBT. Paper presented at the February 2000 Computer-based Testing: Applications for the New Millenium of the Association of Test Publishers., New York.

Kleinmann, M., \& Strauß, B. (1998). Validity and application of computer-simulated scenarios in personnel assessment. International Journal of Selection and Assessment 6(2): 97-106.

Leeson, H. V. (2006). The mode effect: A literature review of human and technological issues in computerized testing. International Journal of Testing, 6(1):1-24.

Mardapi, D., \& Rahmi, E. (2015). European Journal of Educational Research. European Journal of Educational Research, 9(1):293-303.

Ogunlade, O. O., \& Oladimeji, O. F. (2014). Lecturers' perceptions of computer-based test in Nigerian Universities. Global Media Journal: Pakistan Edition, 7(2)

Olatoye, R. (2013). Checking the menace of examination malpractice: A call for more teaching and learning in schools. Retrieved on July, 18.

Onuka, A. O., \& Durowoju, E. O. (2011) Continuous assessment for improved higher education learning achievement in business management. Journal of Pedagogical Thought, 4: 35-52.

Peat, M., \& Franklin, S. (2002). Supporting student learning: the use of computer-based formative assessment modules. British Journal of Educational Technology, 33(5): 515-523.

Resnick, L. B., \& Resnick, D. P. (1992). Assessing the thinking curriculum: New tools for (pp. 37-75): Spring (pp. 37-75): Springer

M. (2012). Attitude of undergraduate students towards computerbased test (cbt): a case study of the university of Ilorin, Nigeria. International Journal of Information and Communication Technology Education (IJICTE), 8(2):33-45 